\title{
A PSICOLOGIA DA PAZ
}

\author{
Mariana Barbosa ${ }^{2}$ \\ Raquel Matos ${ }^{2}$ \\ Carla Machado
}

[Enviado a 08-10-2012. Aceite a 28-02-2013]

Resumo: No presente artigo é feito o enquadramento histórico e concetual da Psicologia da Paz (Peace Psychology). Esta área tem como objetivo a aplicação dos conhecimentos e métodos da Psicologia à prevenção dos conflitos e à promoção dos direitos humanos e da paz. O enfoque da Psicologia nestas temáticas emergiu em pleno contexto de Guerra Fria, quando as preocupações com a hipótese de uma guerra nuclear ser desencadeada levaram alguns psicólogos a contribuir para os esforços de prevenção da guerra e de promoção da paz. Desde então, a Psicologia tem oferecido importantes contributos ao nível da investigação e da intervenção neste domínio, sobretudo no contexto norte-americano. Embora também em grande parte dos países europeus esta área se encontre em franca expansão, em Portugal permanece ainda relativamente desconhecida. Este artigo procura colmatar algum desse desconhecimento.

Palavras-chave: Psicologia da Paz, Direitos Humanos, Violência Estrutural, Paz Positiva

The Psychology of peace (Abstract): This article presents the historical and conceptual context of Peace Psychology. The main goal of this research area is to apply the knowledge and methods of Psychology with a view to prevent conflicts and promote human rights and peace. The psychological focus on such topics took place within the context of the Cold War: concerns about the possibility of a nuclear war encouraged some psychologists to contribute to efforts of war prevention and peace promotion. Since then, Peace Psychology has offered important contributions at the level of research and intervention in this domain, particularly within

\footnotetext{
${ }^{1}$ Artigo elaborado no âmbito de um projeto de investigação financiado pela FCT (SFRM/ $\mathrm{BD} / 30902 / 2006)$.

${ }^{2}$ Faculdade de Educação e Psicologia, Universidade Católica Portuguesa.

${ }^{3}$ Escola de Psicologia, Universidade do Minho.
} 
the United States context. Although in most european countries this research area is booming, it still remains relatively unknown in Portugal.

Keywords: Peace Psychology; Human Rights; Structural Violence; Positive Peace

\section{Introdução}

"Como as guerras se iniciam nas mentes dos homens, é nas mentes dos homens que as defesas da paz devem ser construídas."

(Preâmbulo da Constituição da UNESCO, 1945)

A história da Psicologia ao serviço da guerra é tão antiga quanto a história da própria Psicologia. Tendo a Psicologia o objetivo geral de promover o bem-estar humano, os seus contributos neste âmbito deveriam ser conformes ao repto da UNESCO. No entanto, ao longo da história, os psicólogos foram contribuindo mais para a guerra do que para a paz (Blumberg, Hare \& Costin, 2007; Christie, 2012a; McNair, 2012). Atendendo a que não existirá outro comportamento humano com consequências tão dramáticas, é surpreendente que tenha sido necessário tanto tempo para que a comunidade psicológica colocasse em cima da mesa a questão: se a Psicologia se tem revelado tão útil ao serviço da guerra, porque não sê-lo antes ao serviço da paz?

Compreender e promover a construção da paz é precisamente a missão que os psicólogos da paz escolheram seguir (McNair, 2012). Esta é uma tarefa particularmente ambiciosa, uma vez que a noção de paz, na ótica da Psicologia da Paz, vai além da 'mera' ausência de conflito, pressupondo também um compromisso com os direitos humanos e a justiça social. Além do mais, a crescente internacionalização desta área da Psicologia tem conduzido a uma progressiva diferenciação dos objetivos dos psicólogos da paz em função dos seus contextos geo-históricos de atuação (Christie, 2006).

Como iremos ver, apesar de esta diferenciação concetual e geo-histórica dificultar a delineação e delimitação dos seus objetos de estudo, a Psicologia da Paz tem conseguido avanços notáveis no que concerne à construção de uma identidade própria e diferenciada de outros ramos da Psicologia que lhe são afins (e.g., Psicologia Social, Psicologia Política), constituindo-se, atualmente, como um ramo consolidado da Psicologia. 


\section{Enquadramento histórico}

\section{A Psicologia ao serviço da guerra}

Apesar de a Psicologia da Paz se ter estabelecido como disciplina na década de 80 , ao longo do século XX vários psicólogos haviam abordado já temáticas como o conflito, a violência e a paz.

William James é uma referência incontornável, não só na história geral da Psicologia, como também na história da Psicologia da Paz, uma vez que também nesta área é visto como tendo tido um papel pioneiro. São vários os autores que se referem a James como tendo sido 'o primeiro psicólogo da paz' (e.g., Christie, 2012b; Deutsch, 1995; McNair, 2012). O ensaio 'The Moral Equivalent of War', escrito por James em 1906, voltou a ser publicado na edição inaugural da Peace and Conflict: Journal of Peace Psychology ${ }^{4}$, o que evidencia a relevância dada ao autor no seio da Psicologia da Paz. Neste ensaio, James (1910) surpreendeu a comunidade académica ao referir-se aos 'atrativos da guerra'. De acordo com o autor, a guerra oferece aos indivíduos a oportunidade de expressar virtudes como a lealdade, a hon$\mathrm{ra}$, ou a disciplina. Consequentemente, para acabar com a guerra, seria necessário as sociedades encontrarem 'equivalentes morais' alternativos para a expressão dessas virtudes (Ibidem).

Os psicólogos do início do século não seguiram os conselhos de William James, com o envolvimento inicial da Psicologia nas questões da guerra e da paz a pautar-se, sobretudo, pela contribuição do conhecimento psicológico para os esforços de guerra e não para a procura de alternativas à mesma (Christie, Wagner \& Winter, 2001).

A Primeira Guerra Mundial foi o primeiro palco de um profícuo envolvimento de psicólogos em assuntos militares. Um dos contributos mais importantes da Psicologia neste período foi o desenvolvimento de testes de inteligência que eram usados para selecionar e classificar novos recrutas, desenvolvimento que contribuiu para "colocar a Psicologia no mapa" (Smith, 1986, p. 24, cit. Chrisoe et al., 2001).

$\mathrm{Na}$ Segunda Guerra Mundial os psicólogos intensificaram o seu envolvimento em questões militares. A Psicologia contribuiu para os esforços de guerra de uma forma mais diversificada do que na Primeira Guerra Mundial: desde o desenvolvimento e administração de testes psicológicos para estabelecer as funções e cargos no exército, à intervenção psicológica com militares, ao desenvolvimento de propaganda de guerra e de estratégias

${ }^{4}$ A Peace and Conflict: Journal of Peace Psychology é a principal revista científica da Peace Psychology Division da American Psychological Association. 
para a desmoralização do inimigo e à seleção e treino de indivíduos envolvidos em missões secretas e/ou de espionagem (Christie et al., 2001).

De uma forma geral, os psicólogos foram participantes entusiastas nos esforços para ganhar a Segunda Guerra, por ser percebida como uma 'guerra justa' e pelos ganhos secundários deste envolvimento para a Psicologia, nomeadamente, o reconhecimento da utilidade e importância da profissão, contribuindo, deste modo, para a afirmação da disciplina (Ibidem).

No rescaldo da Segunda Guerra Mundial, foram muitas as vozes, no seio da Psicologia, que começaram a apelar à necessidade de contribuir com o conhecimento psicológico para a prevenção da guerra. Nos Estados Unidos, este apelo deu origem ao The Psychologists' Manifesto: Human Nature and the Peace. Neste manifesto, publicado em 1945 e assinado por cerca de quatro mil psicólogos, eram enumerados dez princípios básicos cruciais para a sustentabilidade da paz, enraizados na premissa de que o potencial humano para a guerra não implica que a mesma seja inevitável. No entanto, aquilo que se seguiu à Segunda Guerra Mundial foi uma 'paz armada', com o emergir de um clima de crescente hostilidade entre duas superpotências (Estados Unidos e União Soviética), que competiam numa corrida ao armamento: a Guerra Fria.

Numa Europa dividida por uma 'cortina de ferro' que metaforizava a profunda rivalidade ideológica entre os dois lados do conflito, os primeiros anos da Guerra Fria foram uma fase de relativa hibernação dos estudos para a paz europeus (Boehnke \& Shani, 2012). Já na psicologia norte-americana, e apesar da mensagem pública de otimismo face às possibilidades de paz, a verdade é que também a generalidade da comunidade psicológica não fugia à lógica da ideologia dominante, a realpolitik, sob a égide da qual o confronto nuclear com a União Soviética era tido como inevitável. Consequentemente, o maior objetivo de grande parte dos psicólogos interessados nestas temáticas era preparar o país para a antecipação de um confronto nuclear com a União Soviética. Assim, também neste período, o papel da Psicologia foi sobretudo de apoio aos esforços de guerra, com um crescente número de psicólogos a desempenhar funções no governo ou no exército. Por exemplo, os psicólogos usavam o seu conhecimento para avaliar e mudar as atitudes do público perante a questão atómica, para lidar com os problemas emocionais experienciados por pessoas expostas aos testes nucleares, ou para reduzir o medo dos soldados e a sua relutância em participar nas manobras nucleares (Rand, 1960, cit. Christie et al., 2001; Schwartz \& Winograd, 1954, cit. Christie et al., 2001).

Alguns psicólogos (e.g. Gordon Allport, Hadley Cantril e Otto Klineberg) tentaram contrariar a lógica fatalista da realpolitik face à possibilidade de uma guerra nuclear, argumentando que a 'era atómica' requeria uma nova forma de diplomacia (Jacobs, 1989, cit. Christie et al., 2001). Havia, no 
entanto, entraves à evolução e disseminação destes esforços. Por um lado, a preocupação dos psicólogos com o próprio desenvolvimento da Psicologia que, como vimos, tinha alcançado um maior estatuto e notoriedade precisamente graças aos seus contributos para os esforços militares nas duas Grandes Guerras. Por outro lado, na década de 50 nos Estados Unidos vivia-se o período do 'Macartismo', durante o qual quem quer que se opusesse às políticas governamentais poderia ser rotulado de comunista e severamente punido, pelo que o clima político da época era pouco ou nada favorável às vozes que se opunham às políticas governamentais vigentes (Christie et al., 2001).

\section{A Psicologia ao serviço da Paz}

No início da década de 60, o pico de tensão atingido com a Crise dos Mísseis de Cuba pôs em evidência que a Guerra Fria tinha atingido um absurdo lógico, já que a corrida ao armamento por parte das duas superpotências culminava numa realidade de 'destruição mutuamente assegurada' (MAD), ou seja, "se uma guerra nuclear ocorresse, o resultado não seria somente a destruição total destas superpotências, mas o fim da vida como a conhecemos" (Christie et al., pp. 8).

Assistiu-se, nesta altura, a uma mudança de paradigma no seio da comunidade psicológica, começando a emergir vozes que desafiavam a mentalidade da Guerra Fria e que reclamavam para a Psicologia o papel de contribuir para a prevenção da guerra e não para a sua preparação (Wagner, 1985; Morawski \& Goldstein, 1985). Em vez de se centrarem em maneiras de assegurar que a opinião pública coincidisse com as considerações da realpolitik, os psicólogos começaram a desenvolver estudos com uma lógica sobretudo preventiva.

Exemplos de contributos que ilustram esta mudança de paradigma são os estudos de autores como Bronfenbrenner (1961), White (1966) e Frank (1967), que alertavam para os perigos do desenvolvimento de imagens diabólicas do inimigo que as pessoas tendem a criar, especialmente quando se sentem ameaçadas. Estes estudos demonstraram que o processo de desumanização do 'Outro' era recíproco, ou seja, as perspetivas negativas dos norte-americanos em relação aos soviéticos eram similares às destes sobre os norte-americanos, formando, dessa forma, uma 'imagem em espelho' uns dos outros (Bronfenbrenner, 1961). Outro contributo importante foi o de Osgood (1962), que propôs o modelo GRIT (Graduated and Reciprocated Initiatives in Tension Reduction), uma estratégia de apaziguamento dos Estados através de um processo alternado de iniciativas de redução do exército e do armamento militar. Também por esta altura, psicólogos clínicos e do desenvolvimento começaram a investigar as implicações, ao nível do desenvolvimento e ao nível da saúde mental, do medo da guerra nuclear (Escalona, 1963, cit. Wessels, 1996; Schwebel, 1965, cit. Wessels, 1996). 
No seio da American Psychological Association (APA) verificaram-se igualmente desenvolvimentos nos esforços em prol da prevenção da guerra nuclear. Numa altura em que não estava ainda criada a Divisão 48 da APA, dedicada à Psicologia da Paz, as ações da APA neste domínio ficaram sob a responsabilidade da Society for the Psychological Study of Social Issues (SPSSI). A SPSSI estabeleceu um 'Comité de Relações Internacionais' e um 'Comité para Controlo de Armas e Desarmamento', e os seus membros foram muito ativos na publicação de estudos sobre questões como a distensão (Deutsch, 1961), o complexo industrial-militar (Pilisuk \& Hayden, 1965) e opinião pública e política externa (Kelman, 1954). Em 1961 a SPSSI dedicou um número do seu Journal of Social Issues a políticas relacionadas com a guerra nuclear e, em 1962, publicou uma edição especial da sua newsletter, intitulada "Psicólogos e Paz", com artigos de autores como Urie Brofenbrenner, Charles Osgood e Morton Deutsch (Wessels, 1996).

Os contributos da Psicologia nesta fase revelaram-se fortemente contrastantes com a generalidade das publicações anteriores sobre a guerra e a paz (Christie et al., 2001; Christie, 2006). Uma das diferenças verificadas foi, desde logo, a deslocação da ênfase do discurso da preparação para a prevenção da guerra. Outra diferença residiu no nível de análise - este passou de um foco exclusivo no comportamento individual para a inclusão de níveis macro de análise (e.g., grupos, organizações, nações). Além disso, estes contributos compreendiam um posicionamento crítico relativamente às políticas governamentais, em oposição à generalidade das investigações anteriores, que, como vimos, tinham a preocupação de contribuir para o consenso público relativamente às políticas vigentes (Morawski \& Goldstein, 1985).

A consciência de que a corrida ao armamento tinha chegado ao ponto de destruição mutuamente assegurada e que, portanto, seria prudente para ambos os lados evitar uma guerra nuclear que ninguém poderia ganhar, levou a que, durante os anos 70, as duas superpotências chegassem a um acordo sobre uma política de distensão, na tentativa de evitar uma catástrofe mundial $^{5}$. No entanto, no início dos anos 80 reacendeu-se a hostilidade nas relações entre os Estados Unidos e a União Soviética, um período que ficou conhecido como Segunda Guerra Fria. Com o objetivo de estabelecer o monopólio nuclear dos Estados Unidos, o Presidente Ronald Reagan propôs o Strategic Defense Initiative (SDI), um programa militar que visava a construção de um sistema de radares e mísseis antibalísticos de longo alcance que constituísse um "escudo espacial" capaz de intercetar, a partir do espaço, quaisquer mísseis balísticos nucleares lançados contra o território dos Estados Unidos.

\footnotetext{
${ }^{5}$ Foi neste âmbito que foi assinado, em 1972, o SALT (Strategic Arms Limitation Talks), entre os Estados Unidos e a União Soviética.
} 
Com a tensão entre as superpotências a aumentar, e tanto os Estados Unidos como a União Soviética a construir novas gerações de armas nucleares, a preocupação pública com a guerra nuclear alcançou níveis sem precedentes. À medida que as tensões se inflamavam, começaram a surgir reações no seio da psicologia e os psicólogos foram questionando, cada vez mais, a sua responsabilidade, como profissionais e como cidadãos, na promoção da paz.

Em 1982, foi criada a Psychologists for Social Responsibility (PsySR), uma organização de natureza ativista independente da APA que foi responsável, na época, pela dinamização de programas educativos sobre questões como a prevenção nuclear, a resolução não violenta de conflitos ou a educação para a paz - e continua a ser, nos dias de hoje, uma das principais redes de psicólogos ativistas em questões relacionadas com os conflitos, os direitos humanos e a paz (Wessels, 1986).

No seio da APA este foi também um período profícuo, no que concerne ao desenvolvimento de estudos relacionados com a guerra nuclear. Em 1982, a SPSSI formou um grupo de trabalho dedicado à questão da paz, que na altura foi responsável pela organização de simpósios sobre esta temática para as convenções da APA e pela edição de um número especial do Journal of Social Issues sobre abordagens positivas à paz (Wagner, de Rivera \& Watkins, 1988).

Outro marco relevante para o desenvolvimento dos contributos da Psicologia nesta área foi a operacionalização do conceito de Perturbação de Stress Pós-Traumático em 1980. Desde aí têm proliferado os estudos sobre a perturbação e seus sintomas, sendo que o facto de estes tenderem a ser mais severos quando o trauma é infligido por outra pessoa do que quando resulta de acidentes ou desastres naturais, conduziu a uma especial atenção aos contextos de guerra, contribuindo, assim, para impulsionar a investigação e intervenção psicológicas neste âmbito.

Em 1984, a APA aprovou uma resolução apelando ao congelamento nuclear e a encorajar os seus membros a serem politicamente ativos na prossecução deste objetivo. Alguns psicólogos enveredaram pelo ativismo político, enquanto outros consideraram que a tomada de posição em tais questões seria extrapolar o conhecimento psicológico existente. Tal como no início do século, muitos psicólogos davam apoio ao exército, mas este grupo estava agora cada vez mais contrabalançado pelo crescente número de psicólogos que trabalhavam no desenvolvimento de opções não militares para lidar com conflitos (McNair, 2012).

O diálogo e a reflexão dos psicólogos sobre as temáticas do conflito e da paz contribuíram para dar credibilidade e legitimidade à aplicação do conhecimento psicológico a estas temáticas, sustentando, deste modo, os esforços de psicólogos pioneiros nos estudos da paz que, de outra forma, se teriam sentido isolados e marginalizados, e oferecendo os alicerces necessários à criação de um ramo da Psicologia dedicado a estas temáticas. 


\section{A consolidação da Psicologia da Paz}

Com o final da Guerra Fria, nos anos 90, a bipolaridade de poder existente, até então, entre as superpotências dissipou-se. A estrutura do planeta havia sido dramaticamente reconfigurada, assim como a natureza da guerra. A tradicional visão da guerra como sendo uma questão de disputa entre Estados tornou-se limitada, com a maioria das situações de conflito após a Guerra Fria a ocorrerem dentro dos Estados, relacionando-se, "não tanto com as fronteiras do Estado, mas com a etnia, a religião, o bem-estar económico, a densidade populacional e a sustentabilidade ambiental" (Klare, 1998, cit. in Christie, et al., 2001, pp. 12).

A emergência e a disseminação destes novos problemas propiciaram um contexto favorável à criação, no seio da APA, da Divisão de Psicologia da $\mathrm{Paz}^{6}$, e reforçaram a necessidade de reorientar e ampliar o espectro de investigação e de ação da disciplina (Christie, et al., 2001). A Psicologia da Paz afastou-se progressivamente de uma atividade teórica e prática muito centrada nas questões nucleares, começando-se a considerar um leque mais geral de ameaças e oportunidades que constrangem o bem-estar e a sobrevivência do ser-humano, pelo que os investigadores sentiram necessidade de complexificar as noções de violência e de paz, abarcando diferentes dimensões e níveis de análise (Christie, 2006). A paz na Psicologia da Paz passou a ser entendida dentro de uma grelha muito mais compreensiva que vai além da 'mera' ausência de conflito, pressupondo, também, um compromisso com os direitos humanos e a justiça social.

Christie et al. (2001, p. 13) propõem uma definição de Psicologia da Paz que ilustra bem a complexidade e diversidade da disciplina na atualidade: "A Psicologia da Paz procura desenvolver teorias e práticas dirigidas à prevenção e mitigação de violência direta e estrutural. Definida de uma forma positiva, a Psicologia da Paz promove a gestão não violenta dos conflitos e a procura da justiça social, ou seja, o peacemaking e o peacebuilding, respetivamente". Surgem nesta definição alguns conceitos - violência direta e estrutural, peacemaking e peacebuilding - que importa desenvolver um pouco, na medida em que remetem para os quatro grandes domínios de investigação e intervenção da Psicologia da Paz. Esta terminologia, adotada não só pelos psicólogos como pelos estudiosos da paz em geral, deriva do trabalho pioneiro de Johan Galtung, um dos fundadores da área geral dos peace studies, e, uma vez que são fundamentais para situar o leque de atuação da Psi-

${ }^{6}$ Society for the Study of Peace, Conflict, and Violence: Peace Psychology Division of the American Psychological Association. 
cologia da Paz, dedicaremos, de seguida, algum espaço deste artigo à diferenciação destes conceitos.

\section{Enquadramento concetual}

Galtung (1969) diferencia dois tipos de violência, a direta e a estrutural. A primeira refere-se à violência física que lesa ou mata pessoas de forma rápida, instrumental e intencional, produzindo trauma somático ou incapacitação total (Christie, 2006). Já a violência estrutural refere-se à ofensa crónica à integridade do ser humano que tem origem nas estruturas económicas e políticas da sociedade, ocorrendo quando as pessoas são vítimas de opressão política, exploração económica ou subjugação social. Galtung (1969) propôs que uma forma de aferir os níveis de violência estrutural seria calcular o número de mortes evitáveis. Por exemplo, se há pessoas que morrem por pernoitarem na rua em condições climatéricas adversas, mas existem condições para abrigá-las, então temos um problema de violência estrutural.

Christie (2001) aponta algumas diferenças entre a violência direta e a violência estrutural que permitem uma leitura mais compreensiva de ambos os conceitos. Enquanto a violência direta é, geralmente, dramática e pessoal, a violência estrutural é menos óbvia e impessoal. A violência direta ocorre de uma forma mais intermitente do que a violência estrutural, que tem um caráter mais contínuo. A violência direta tem consequências mais concretas e imediatas, enquanto a violência estrutural tem consequências lentas e difusas. Um exemplo desta violência serão as taxas desproporcionalmente elevadas de mortalidade infantil em determinadas zonas geográficas. É possível inferir a presença de intencionalidade em casos de violência física, sendo mais difícil fazê-lo nos casos de violência estrutural, o que dificulta a criminalização dos mesmos.

Apesar de termos enfatizado distinções entre violência direta e estrutural, a relação entre as duas é circular. Estes dois tipos de violência influenciam-se mutuamente: danos humanos (mortes, feridos, desalojados) e estragos materiais - violência direta - reforçam a violência estrutural (Galtung, 1990) que, por sua vez, pode aumentar a violência direta. Por exemplo, no período do Apartheid, um branco que maltratasse fisicamente um negro estava não só a exercer violência direta, como a exercer sobre ele um domínio hierárquico que era sustentado pelas narrativas de discriminação racial vigentes, na altura, na África do Sul. Simultaneamente, os seus atos violentos contribuíam para reforçar a conjuntura social que colocava os brancos numa posição de domínio em relação aos negros. Violência direta e violência estrutural não são, de facto, fenómenos que ocorrem de forma isolada, operando, antes, de forma conjunta, formando um sistema interligado de violência.

Com a crescente diferenciação entre a violência direta e a estrutural, a visão tradicional da paz como significando ausência de violência direta tor- 
nou-se limitada. A esta conceção tradicional de paz, que Galtung (1990) denominou 'negativa', o autor acrescentou a noção de 'paz positiva'. A paz negativa existe quando, após um conflito, cessa a violência direta mas permanece a violência estrutural. Já a paz positiva pressupõe também a ausência de violência estrutural. Deste modo, a paz positiva apenas está presente quando o Estado zela pelos direitos humanos e pela inclusão social (ibidem). Percebemos, assim, que, na perspetiva de Galtung, a ausência de violência direta não significa paz. Por exemplo, o "cessar-fogo" pode ser considerado um período entre duas guerras, uma vez que podem permanecer conflitos estruturais que poderão desencadear novas vagas de violência direta.

A evolução da concetualização da violência e da paz levou à diferenciação dos processos de paz, sendo importante dar aqui conta dos processos de peacemaking e peabuilding (Christie, Tint, Wagner \& Winter, 2008). O peacemaking consiste nas tentativas de prevenir ou mitigar a violência direta através da promoção da resolução não violenta de conflitos. Teóricos e práticos contemporâneos da resolução de conflitos veem o conflito como uma questão essencialmente percetiva, com o conflito a instalar-se quando dois ou mais lados percecionam os seus objetivos como sendo incompatíveis. Deste modo, apesar de os conflitos poderem levar à violência, uma situação de conflito, em si mesma, não torna a violência inevitável (Ibidem).

Aquilo que se procura na resolução de conflitos é que as partes sejam capazes de usar a situação como uma oportunidade para uma resolução criativa do problema que possa beneficiar ambas as partes, em simultâneo ou de forma alternada, evitando a gestão do conflito de formas que poderiam comprometer a relação entre as partes (Rubin \& Levinger, 1995; cit. Christie et al., 2008). Quando os esforços de resolução de conflitos falham e/ou não chegam a existir, e ocorrem de facto episódios violentos, importa, antes de mais, cessar a violência. No entanto, é também essencial a intervenção pós-conflito, de forma a prevenir a ocorrência de novos episódios violentos e interromper o ciclo de violência. É importante atender a dimensões psicológicas, sociais, políticas e económicas dos problemas desencadeados por episódios violentos, passando por questões relacionadas, por exemplo, com a intervenção no trauma de guerra ou com a reconciliação em sociedades divididas.

Apesar da inegável importância dos esforços de peacemaking, esta é uma abordagem com limitações, entre elas o fato de facilmente poder ser utilizada como uma ferramenta por aqueles que estão em posições de poder e que podem insistir em meios pacíficos para resolver disputas, de forma a manter o status quo vigente, mas ignorando os fins socialmente justos. $\mathrm{O}$ processo de diálogo que caracteriza as abordagens de peacemaking é importante, mas uma paz sustentável requer o peacebuilding estrutural e cultural, ações dirigidas às causas mais profundas e permanentes do problema da injustiça social (Christie et al., 2001; Galtung, 1990). 
Enquanto o peacemaking se refere a um conjunto de ações que visam reduzir a violência direta, o peacebuilding é concebido para reduzir a violência estrutural. O peacemaking foca-se nos 'meios', tendo o objetivo de que sejam utilizados meios não violentos na resolução dos conflitos, enquanto o peacebuilding enfatiza os 'fins', tendo o objetivo de que estes sejam socialmente justos (Galtung, 1990). Ao contrário do peacemaking, que tende a ser um processo reativo, em função da ameaça ou uso efetivo de violência direta, o peacebuilding é um processo continuado no tempo e no espaço, uma vez que a prossecução da justiça social passa necessariamente por transformações profundas nas estruturas económicas, políticas e sociais que exploram e privam as pessoas da satisfação das suas necessidades básicas (Ibidem). Culturalmente, o peacebuilding requer a transformação de crenças ou narrativas culturais que alimentam o domínio de um grupo sobre outro. Politicamente, o peacebuilding requer a transformação dos sistemas políticos opressores que limitam direitos cívicos, como a liberdade de expressão ou a representação política. O peacebuilding pressupõe, ainda, transformação das estruturas económicas que exploram e privam as pessoas de recursos necessários ao crescimento e desenvolvimento sustentáveis (Christie et al., 2001). Facilmente se compreenderá que o processo de peacebuilding possa, assim, ser profundamente ameaçador para as relações de poder e ordem social vigentes numa dada sociedade.

Sendo a violência direta e a violência estrutural processos interligados e cíclicos, os processos de peacemaking e de peacebuilding acabam por se influenciar mutuamente. Os esforços de peacemaking poderão reduzir a probabilidade da violência estrutural no pós-conflito. Por outro lado, os esforços de peacebuilding poderão prevenir a violência direta através da eliminação das suas bases estruturais. Tal como foi já referido, existe o perigo de uma utilização perversa dos esforços de peacemaking por parte daqueles que estão em posições de poder e que podem insistir em meios pacíficos para resolver disputas, de forma a manter o status quo vigente, mas ignorando os fins socialmente justos. Nestes casos, o peacemaking, a ocorrer de forma isolada, estará a contribuir para a perpetuação das desigualdades, daí decorrendo a importância de os esforços de peacemaking terem lugar no contexto de esforços de peacebuilding (Winter, Christie, Wagner \& Boston, 2001).

\section{A internacionalização da Psicologia da Paz}

A crescente internacionalização da Psicologia da Paz tem levado à procura de uma cada vez maior sensibilidade cultural na forma de delinear e providenciar as respostas interventivas, pela consciencialização de que estas só irão responder às necessidades de cada contexto se atenderem às suas especificidades culturais. Assim, por exemplo, nos esforços interventivos na resolução de conflitos e na reconciliação pós-conflito em países do sudoeste 
Asiático e da América Latina, a Psicologia da Paz tende a dar primazia ao coletivismo sobre o individualismo e às subjetividades partilhadas, mais do que às abordagens objetivas, características da psicologia ocidental tradicional (Montero \& Sonn, 2009; Montiel \& Noor, 2009; Montiel, 2012). Já no contexto africano, e no que concerne à reconstrução pós-conflito, a Psicologia da Paz enfatiza a ação participativa, baseada na comunidade e enraizada culturalmente, honrando as tradições e sabedoria locais (Heuchert, 2012; Wessells \& Montiero, 2004).

Este processo tem, também, levado à definição dos objectivos de atuação, atendendo àquelas que são as problemáticas e preocupações centrais num dado contexto. Por exemplo, e remetendo-nos ao contexto europeu, o desmembramento da Jugoslávia desafiou os psicólogos da paz a compreenderem as variáveis geohistóricas e motivacionais por detrás da disseminação da violência. Além disso, foram enviados psicólogos para o terreno, em esforços para ajudar as vítimas a lidar com o trauma de guerra (Hare, 2006; cit. Boehnke \& Shani, 2012). O conflito entre a maioria Protestante e a minoria Católica na Irlanda do Norte também tem merecido a atenção da Psicologia da Paz, que tem procurado contribuir com a prática psicológica para os esforços de resolução de conflitos e de reconciliação entre as duas fações (e.g., promoção de diálogo entre vítimas e militares, mediação de conflitos, programas de educação para a paz, desenvolvimento de iniciativas que impliquem a interação entre católicos e protestantes). Aos esforços interventivos acrescem os esforços desenvolvidos em prol da contribuição do conhecimento psicológico para a compreensão do conflito, de que são exemplos a aplicação da teoria da categorização social à divisão político-religiosa da Irlanda do Norte, ou o estudo do impacto do conflito na saúde mental de crianças e adultos (Cairns, Wilson, Gallagher \& Trew, 1995; cit. Christie et al., 2008). Outros exemplos de contributos da Psicologia da Paz na europa são o estudo do papel da identidade de grupo nas relações conflituosas entre gregos e turcos, o treino e consultoria na resolução de conflitos em regiões como o Chipre ou a Estónia, ou trabalhos sobre o trauma pós-guerra na Macedónia (Christie et al., 2008).

No que diz respeito ao panorama português, verifica-se que a Psicologia da Paz é ainda uma área relativamente desconhecida. Carla Machado teve um importante contributo para impulsionar a investigação neste domínio em Portugal. A autora coordenou a equipa de investigação portuguesa do Group on International Perspectives on Governmental Aggression and Pea$c e$, um projeto que está a ser conduzido em cerca de cinquenta países de todo o mundo e de todos os continentes. Para além de procurar perceber o grau de tolerância de cidadãos-comuns em relação a diferentes formas de violência de Estado e os mecanismos discursivos envolvidos nesta legitimação, este projeto visa também compreender o seu posicionamento face às possibilida- 
des de paz e reconciliação (Barbosa, Machado, Matos \& Barbeiro, 2012). Têm sido levadas a cabo análises comparativas entre cidadãos de diferentes áreas geográficas e de diferentes países, de forma a identificar, no discurso dos participantes, quais os aspetos que são transversais aos vários países e quais os aspetos que se diferenciam em função das especificidades histórico-culturais dos mesmos. Os resultados deste estudo têm dado origem a diversas publicações internacionais entre as quais se destacam dois volumes da Peace Psychology Book Series (Malley-Morrison, McCarthy \& Hines, 2013; Malley-Morrison, Mercurio \& Twose, 2013), uma coleção da Springer coordenada por Daniel Christie, um autor de referência no âmbito da Psicologia da Paz.

\section{Conclusão}

A perspetiva diferenciada dos conceitos de violência e paz conduziu à diferenciação de objetos de estudo da Psicologia da Paz e, consequentemente, à amplificação dos seus objetivos, contextos e alvos de intervenção. A paz na Psicologia da Paz passou a ser entendida dentro de uma grelha muito mais compreensiva, que requer que se atenda não apenas a preocupações tradicionais sobre resolução não violenta de conflitos, como também a preocupações crescentes relacionadas com a busca de justiça social. Aos esforços de compreensão dos conflitos, olhando às suas expressões violentas, como sejam os atos de tortura, de terrorismo ou de violência policial, juntaram-se análises da influência de fatores geradores de violência estrutural, tais como a pobreza, os fluxos migratórios ou as desigualdades sociais. Amplificando-se as dimensões em análise, amplificam-se também os contextos e alvos de intervenção, com a Psicologia da Paz, na procura de respostas de intervenção, a atender não apenas às vítimas de violência direta (e.g., vítimas de tortura) como também às vítimas de violência estrutural (e.g., sem-abrigo).

A diferenciação conceptual e geo-histórica da Psicologia da Paz tem imposto dificuldades acrescidas a uma disciplina que chamou a si a missão de promover a construção da paz. Se a prevenção dos conflitos violentos seria um objetivo já de si ambicioso, a inclusão dos esforços de peacebuilding com vista à promoção da justiça social coloca a Psicologia da Paz perante uma missão que poderá ser percebida por muitos como utópica ou idealista. No entanto, como perguntam Winter, Christie, Wagner e Boston (2001): haverá algo de mais importante? 


\section{Bibliografia}

Barbosa, M., Machado, C., Matos, R., R Barbeiro, A. (2012). Discursos sociais sobre a violência de Estado: um estudo qualitativo. Análise Psicológica, $X X X$ (1-2), 215-230.

Blumberg, H. H., Hare, A. P. \& Costin, A. (2007). Peace Psychology: a comprehensive introduction. Cambridge: University Press.

Boehnke, K. \& Shani, M. (2012). Peace psychology: Contributions from Europe. In D. Christie (Ed.), Encyclopedia of peace psychology, Hoboken, NJ: Wiley-Blackwell.

Bronfenbrenner, U. (1961). The mirror image in Soviet-American relations: A social psychologist's report. Journal of Social Issues, 17(3), 45-56.

Christie, D. J. (2001). Structural peacebuilding: Psychology and the pursuit of social justice. In D. J. Christie, R. V. Wagner, \& D. A. Winter (Eds.), Peace, Conflict, and Violence: Peace Psychology for the 21st Century (pp. 277-281). Englewood Cliffs, New Jersey: Prentice-Hall.

Christie, D. J. (2006). What is peace psychology the psychology of? Journal of Social Issues, 62(1), 1-17.

Christie, D. J. (2012a). Peace psychology: Definitions, scope, and impact. In D. Christie (Ed.), Encyclopedia of peace psychology, Hoboken, NJ: Wiley-Blackwell.

Christie, D. J. (2012b). Peace psychology: Contributions from North America. In D. Christie (Ed.), Encyclopedia of peace psychology, Hoboken, NJ: Wiley-Blackwell.

Christie, D. J., Tint, B. S., Wagner, R. V. \& Winter, D. D. (2008). Peace psychology for a peaceful world. American Psychologist, 63(6), 540-552.

Christie, D. J., Wagner, R. V., \& Winter, D. A. (2001). Introduction to peace psychology. In D. J. Christie, R. V. Wagner, \& D. A. Winter (Eds.), Peace, Conflict, and Violence: Peace Psychology for the 21st Century (pp. 1-14). Englewood Cliffs, New Jersey: Prentice-Hall.

Deutsch, M. (1961). Some considerations relevant to national policy. Journal of Social Issues, 17(3). 57-68.

Deutsch, M. (1995). William James: The first peace psychologist. Peace and Conflict: Journal of Peace Psychology, 1, 27-36.

Frank, J.D. (1967). Sanity and survival in the nuclear age. New York: Random House.

Galtung, J. (1969). Violence, peace and peace research. Journal of Peace Research, 3, 176-191.

Galtung, J. (1990). Violence and peace. In P. Smoker, R. Davies, \& B. Munske (Eds.), A reader in peace studies (pp. 9-14). New York: Pergamon.

Heuchert, J. W. P. (2012). Peace psychology: Contributions from Africa. In D. Christie (Ed.), Encyclopedia of peace psychology, Hoboken, NJ: Wiley-Blackwell. 
James, W. (1995/1910). The moral equivalent of war. Peace and Conflict: Journal of Peace Psychology, 1, 17-26.

Malley-Morrison, K., McCarthy, S. \& Hines, D. (2013). International handbook of war, torture, and terrorism (Peace Psychology Book Series). New York: Springer.

Malley-Morrison, K., Mercurio, A. \& Twose, G. (2013). International handbook of peace and reconciliation (Peace Psychology Book Series). New York: Springer.

Kelman, H. C. (1954). Public opinion and foreign policy decisions: some problems for research. Bulletin of Research Exchange on Prevention of War, 2(4), 2-8.

McNair, R. (2012). The Psychology of Peace: an introduction. Westport: Praeger.

Montero, M., \& Sonn, C. C. (2009). Psychology of liberation: Theory and applications. New York, NY: Springer.

Montiel, C. J. (2012). Peace psychology: Contributions from Asia. In D. Christie (Ed.), Encyclopedia of peace psychology, Hoboken, NJ: Wiley-Blackwell.

Montiel, C. J., \& Noor, N. M. (2009). Peace psychology in Asia. New York, NY: Springer.

Morawski, J. G., \& Goldstein, S. E. (1985). Psychology and nuclear war: a chapter in our legacy of social responsibility. American Psychologist, 40, 276-284.

Osgood, C.E. (1962). An alternative to war or surrender. Urbana, IL: University of Illinois Press.

Pilisuk, M. \& Hayden, T. (1965). Is there a military-industrial complex which prevents peace? Consensus and countervailing power in pluralistic systems. Journal of Social Issues, 21(3), 67-117.

Wagner, R.V. (1985). Psychology and the threat of nuclear war. American Psychologist, 40, 531-535.

Wagner, R. V., de Rivera, J. \& Watkins, M. (Eds). (1998). Psychology and the promotion of peace. Journal of Social Issues, 44(2). 1-219.

Wessells, M. G. (1996), A history of Division 48: Peace Psychology. In D. Dewsbury (Ed.). Unification through division: histories of the divisions of the American Psychological Association (pp. 265-294). Washington, D. C.: American Psycholigical Association.

Wessells, M. \& Monteiro C. (2004). Healing the wounds following protracted conflict in Angola: A community-based approach to assisting war-affected children. In U. P. Gielen, J. Fish, \& J. G. Draguns (Eds.), Handbook of culture, therapy, and healing (321-341). Mahwah, NJ: Erlbaum.

White, R.K. (1966). Misperception and the Vietnam War. Journal of Social Issues, 22(3), 1-164.

Winter, D. D., Christie, D. J., Wagner, R. V., and Boston, L. B. (2001). Peace psychology for the 21 st century. In D. J. Christie, R. V. Wagner, \& D. A. Winter (Eds.), Peace, Conflict, and Violence: Peace Psychology for the $21^{\text {st }}$ Century (pp. 363-371). Englewood Cliffs, New Jersey: Prentice-Hall. 